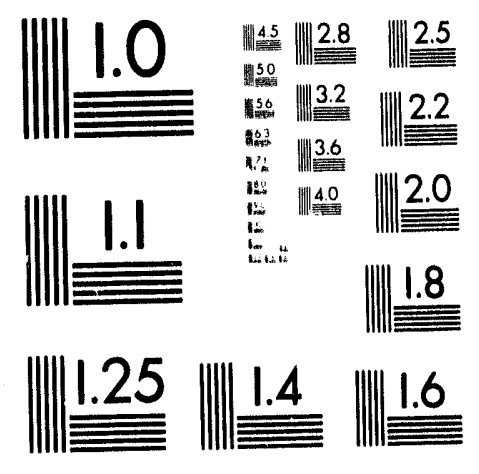



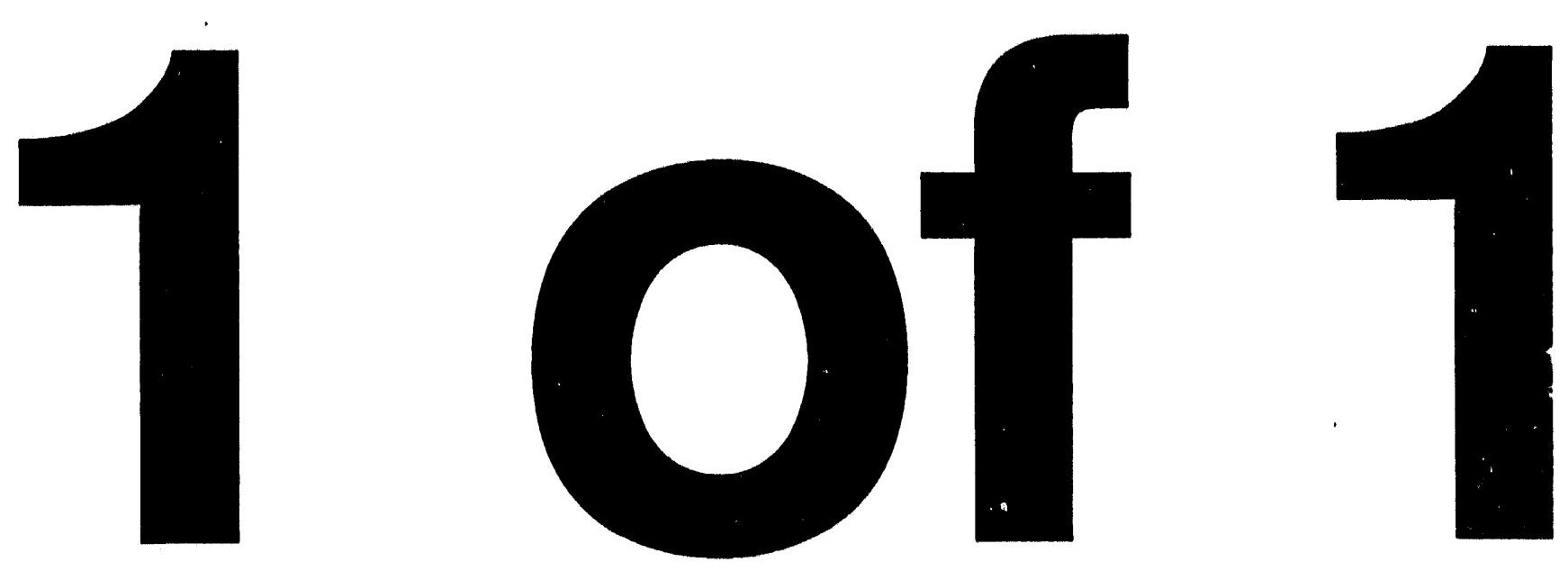


\title{
APPLICATIONS OF COAL-MINERAL ASSOCIATION DETERMINED BY SEM-AIA \\ TO PHYSICAL COAL CLEANING
}

\author{
W. E. Straszheim \\ Fossil Energy Program \\ Ames Laboratory \\ Ames, IA 50011
}

\begin{abstract}
Analysis of the association of minerals with coal using scanning electron microscope-based automated image analysis (SEM-AIA) is described and applied to physical coal cleaning. Results are expressed with regard to both density-based and surface-based cleaning processes.

Samples of nominal 200-mesh Pittsburgh No. 8 coal used in column flotation experiments were analyzed by SEM-AIA to predict cleanability for both types of cleaning and for individual minerals. Results indicated good liberation of minerals based on particle mineral matter content and thus predicted good cleanability by density-based methods. Results also showed poor liberation of pyrite compared to other minerals when particles were categorized according to surface appearance, thus indicating poor cleanability. Predictions were generally borne out by actual separations although additional factors besides liberation appear to be hindering the cleanability of pyrite by column flotation.
\end{abstract}

\section{INTRODUCTION}

Advanced coal preparation requires significantly more understanding of the feed material to a processing circuit than is typically available using conventional analyses. When such understanding is lacking, the result can be a "hit-or-miss" approach to process development where conditions are changed in a more-or-less methodical manner in an effort to achieve higher recoveries of coal while also achieving a better separation of coal from ash-forming minerals. In many cases the difficulties with obtaining a better separation are related fundamentally to the distribution and association of the mineral matter within the coal. For a given particle size there is a real limit beyond which the coal cannot be cleaned. For density-based cleaning processes this limit is expressed as a washability curve determined by controlled float-sink separations. For surface-based processes this limit is expressed as a release analysis curve. Both express the maximum cleaning possible for a given level of recovery under ideal conditions. 
Such expressions of cleanability are good. However, they can be time consuming to derive and must be repeated for every particle size. Current capabilities in scanning electron microscopy, $x$-ray analysis, and image analysis permit derivation of similar information, but on an individual mineral basis, and along with insight into the particle size so that cleanability can be extrapolated to finer sizes, as necessary $[1,2]$.

\section{METHODS}

Scanning electron microscope-based automated image analysis (SEM-AIA) operates by characterizing a polished section of coal and mineral matter. Approximately one gram of coal sample at the particle size of interest is mixed with five grams of binder and allowed to harden. The hardened samples are polished using standard petrographic procedures and coated with a thin layer of carbon (i.e., $15 \mathrm{~nm}$ ) to provide a conductive surface for SEM examination.

The pellets differ from standard petrographic mounts in two ways. First, pellets are sectioned vertically to accommodate the settling of large, dense particles that can occur while the binder solidifies. Secondly, normal epoxy is not suitable as a binder since it does not exhibit adequate contrast with the coal in the SEM backscattered electron (BSE) image. Therefore, both carnauba wax [3] and iodoform-doped epoxy resin [4] have been used to achieve contrast. The carnauba wax has a lower average atomic number than the coal and thus shows up darker in a BSE image; however, the wax pellets are somewhat difficult to prepare and polishing characteristics are only fair. The iodoform-doped epoxy has a higher atomic number than coal and shows up brighter than the coal and yet darker than the minerals in a BSE image. Polishing characteristics are good and there are only slight problems with controlling the arnount of iodoform in solution with the epoxy.

Pellets are examined in a system consisting of a JEOL $840 \mathrm{~A}$ scanning electron microscope, a KEVEX Delta V energy-dispersive x-ray analyzer with a Quantum ${ }^{\text {tm }}$ light element detector, and a LeMont Scientific image analyzer. Samples are imaged using an electron beam of $15 \mathrm{kV}$ and $1 \mathrm{nA}$ which provides adequate contrast for automatic differentiation of minerals, coal, and background based on brightness thresholds.

Fields are examined stereologically at magnifications ranging from $50 x$ to $300 x$ depending on the resolution required for the particle range being characterized. For each field, the coal and mineral particles are located based on their brightness. Particle area, perimeter, location, etc. are noted for each particle. In particular, the arrangement or association of mineral grains with respect to the coal matrix are noted. Data for a composite coal-mineral feature includes the sizes of the constituent parts and the sharing of perimeter among the parts. That is, for each mineral particle, the amount of perimeter bounded by coal or exposed to the binder is recorded. Following stereological characterization, a brief (2 second) $x$-ray spectrum is collected for each mineral grain. With an $x$-ray count rate of 2000 counts per second, this allows qualitative identification of the particle based on the relative intensity of the elements present. Twenty elements, including aluminum, silicon, sulfur, iron, calcium, and oxygen are used to identify the particles based on their relative intensities into one of twenty particle classes (e.g., pyrite, iron sulfate, 
kaolinite, quartz). Particles are then assigned a density which is used to convert the measured area fractions into density fractions.

Multiple frames are analyzed at each magnification so that a complete analysis for a coal includes data on thousands of composite coal-mineral grains for statistical significance and requires about 12 hours of instrument time per sample.

The sample of Pittsburgh No. 8 coal used in this work was ground to $75 \%$ passing 200-mesh, has an ash content of $27 \%$, a total sulfur content of $4.6 \%$, and a pyritic sulfur content of $2.9 \%$. A portion of the coal was split into density fractions using Certigrav of 1.3 and 1.6 specific gravity for centrifugal float-sink separations. The coal was also cleaned using a $50 \mathrm{~mm}$ (2-inch) diameter, $6 \mathrm{~m}$ (20-foot) high bench scale column flotation system. Coal was fed as a $5 \%$ slurry at $400 \mathrm{ml} / \mathrm{min}$. MIBC was used as a frother at a rate of $0.05 \%$, (i.e., one lb. per ton of coal). Air was introduced near the bottom of the column at $1 \mathrm{l} / \mathrm{min}$. Counter-current wash water was introduced near the top of the column at $400 \mathrm{ml} / \mathrm{min}$.

\section{RESULTS AND DISCUSSION}

AIA data were classified according to three different schemes which each provide different insights into the coal.

First, particles were classified according to particle size (area-equivalent diameter) and phase. Results are shown in Table 1 and Figure 1. This scheme presents some insight into the particle size necessary for liberation. However, sometimes minerals can be selectively liberated so that a coarser particle size would be sufficient. In this sample, pyrite is relatively coarse while the clays kaolinite and illite are rather fine. Therefore, the pyrite would be expected to be more 'liberated' from the coal than the clays. However, liberation depends on the distribution of the minerals within the coal matrix and not on particle size alone.

\section{TABLE 1}

Size distribution (area-equivalent diameter, $\mu \mathrm{m}$ ) of coal and minerals in 200-mesh Pittsburgh No. 8 coal (wt.\%, dry)

\begin{tabular}{|c|c|c|c|c|c|c|c|}
\hline Category & $0-4$ & $4-7$ & $7-12$ & $12-21$ & $21-36$ & $>36$ & Sum \\
\hline Coal & 7.37 & 5.41 & 6.64 & 8.11 & 11.10 & 29.10 & 67.75 \\
\hline Mineral Matter & 5.05 & 4.10 & 4.86 & 4.78 & 4.99 & 8.47 & 32.25 \\
\hline \multicolumn{8}{|c|}{ Where "Mineral Matter" includes: } \\
\hline Pyrite & 0.57 & 0.42 & 0.74 & 1.19 & 1.65 & 3.52 & 8.08 \\
\hline Kaolinite & 0.61 & 0.55 & 0.67 & 0.62 & 0.42 & 0.93 & 3.80 \\
\hline Illite & 1.05 & 0.87 & 0.83 & 0.54 & 0.90 & 0.95 & 5.14 \\
\hline Quartz & 0.74 & 0.88 & 1.25 & 0.99 & 0.69 & 1.01 & 5.55 \\
\hline Calcite & 0.04 & 0.06 & 0.06 & 0.13 & 0.28 & 0.12 & 0.70 \\
\hline Silicates & 0.73 & 0.79 & 0.67 & 0.93 & 0.53 & 1.16 & 4.82 \\
\hline Other & 1.31 & 0.53 & 0.63 & 0.39 & 0.52 & 0.78 & 4.16 \\
\hline Total & 12.42 & 9.51 & 11.50 & 12.89 & 16.09 & 37.57 & 100.00 \\
\hline
\end{tabular}




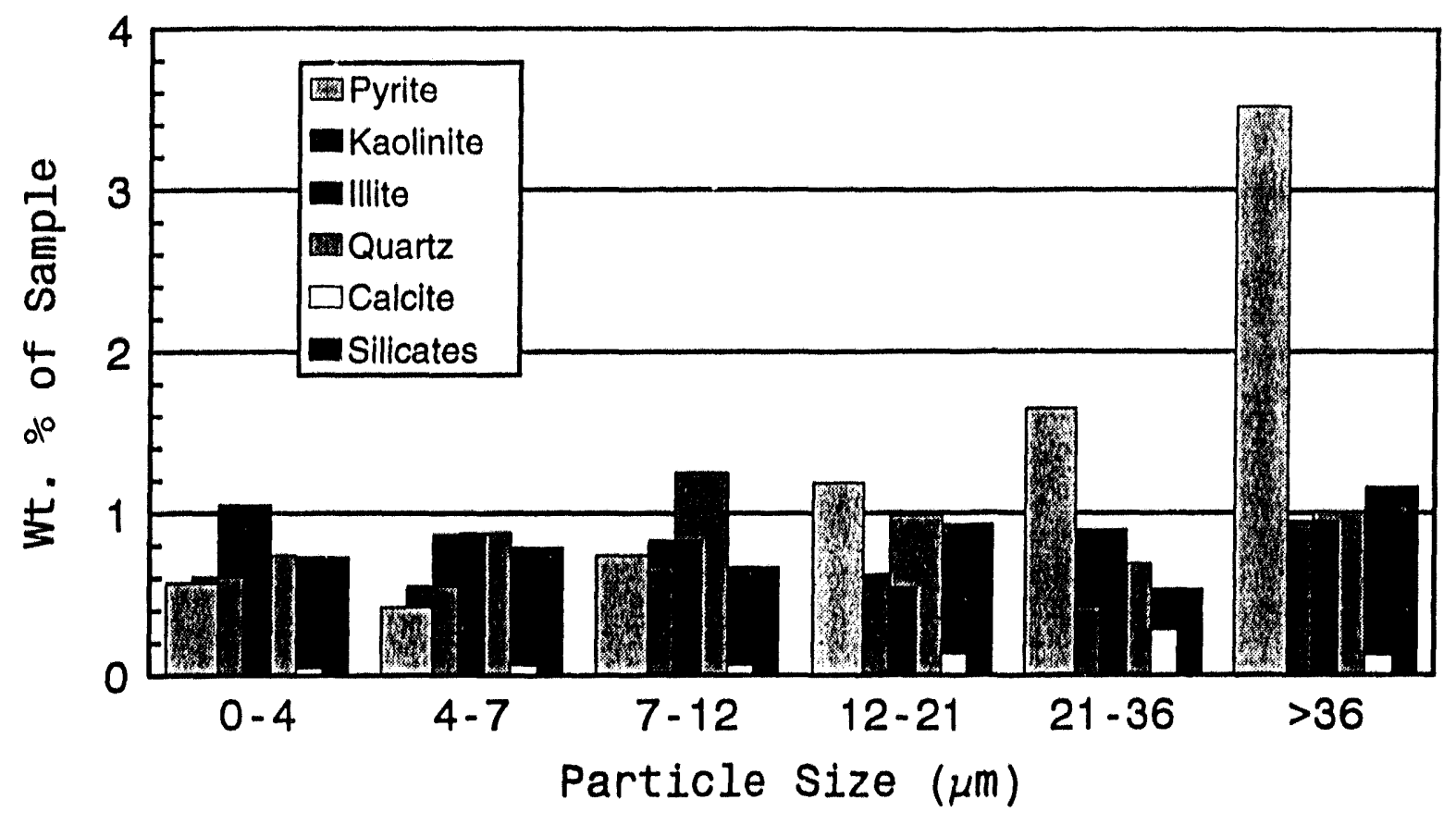

Fig. 1. Size distribution of minerals in 200-mesh Pittsburgh No. 8 coal.

Second, particles were classified according to the weight fraction of mineral matter present in them. Particle mineral matter content determines the particle density; therefore, this mode of expression is helpful for predicting the behavior in densitybased cleaning processes. The results for this sample are shown in Table 2, and in Figure 2 using the data from the top two rows of Table 2. Figure 2 indicates that the bulk of the minerals are concentrated in particles with a mineral content of more than $80 \%$. The broad gap between coal-rich particles on the left side of the figure and mineral-rich particles on the right indicates good liberation and fairly easy cleaning. That is, there is relatively little middlings material containing $20-80 \%$ mineral matter in the particles. Thus, change in the effective density of separation should not result in drastic changes in the recovery or mineral rejection.

Third, particles are classified according to the amount of mineral matter found on the suriace by SEM-AIA. The less of a particle surface occupied by coal, the more likely it is to be rejected as tallings in a surface-based cleaning process. Admittedly, other factors will act to determine a particle's path through a cleaning process; however, this provides one estimate of the cleaning behavior on a very fundamental level. The results for this sample are shown in Figures 3 and 4; Figure 3 shows the association of coal and minerals without regard to mineral type and Figure 4 shows the distribution of the significant minerals.

Figure 3 indicates much less distinction between particles destined for clean coal (left side) and tailings (right side) streams. There is a significant amount of 'middlings' particles in the center of the figure. To the degree that it is possible to establish separation conditions to split the sample according to the amount of mineral coverage of the particles, the outcome of the separation will be much more sensitive to the placement of the cut point in terms of product quantity and quality. 
TABLE 2

Distribution of coal and minerals in 200-mesh Pittsburgh No. 8 coal based on mineral matter content of the particles ( $w t . \%$ of dry coal)

\begin{tabular}{|c|c|c|c|c|c|c|c|}
\hline \multicolumn{8}{|c|}{ Particle MM Content, \% } \\
\hline Category & 0 & $1-20$ & $21-40$ & $41-60$ & $61-80$ & $81-100$ & Sum \\
\hline Coal & 42.89 & 17.73 & 2.61 & 1.82 & 1.35 & 1.36 & 67.75 \\
\hline Mineral Matter & 0.00 & 1.18 & 1.03 & 1.81 & 3.28 & 24.94 & 32.25 \\
\hline \multicolumn{8}{|c|}{ Where "Mineral Matter" includes: } \\
\hline Pyrite & 0.00 & 0.36 & 0.17 & 0.40 & 0.46 & 6.69 & 8.08 \\
\hline Kaolinite & 0.00 & 0.16 & 0.17 & 0.13 & 0.25 & 3.08 & 3.80 \\
\hline Illite & 0.00 & 0.11 & 0.15 & 0.34 & 0.86 & 3.69 & 5.14 \\
\hline Quartz & 0.00 & 0.16 & 0.19 & 0.27 & 0.55 & 4.38 & 5.55 \\
\hline Calcite & 0.00 & 0.01 & 0.02 & 0.07 & 0.13 & 0.47 & 0.70 \\
\hline Silicates & 0.00 & 0.13 & 0.12 & 0.34 & 0.64 & 3.59 & 4.82 \\
\hline Other & 0.00 & 0.26 & 0.21 & 0.27 & 0.40 & 3.03 & 4.16 \\
\hline Total & 42.89 & 18.91 & 3.64 & 3.63 & 4.63 & 26.30 & 100.00 \\
\hline
\end{tabular}

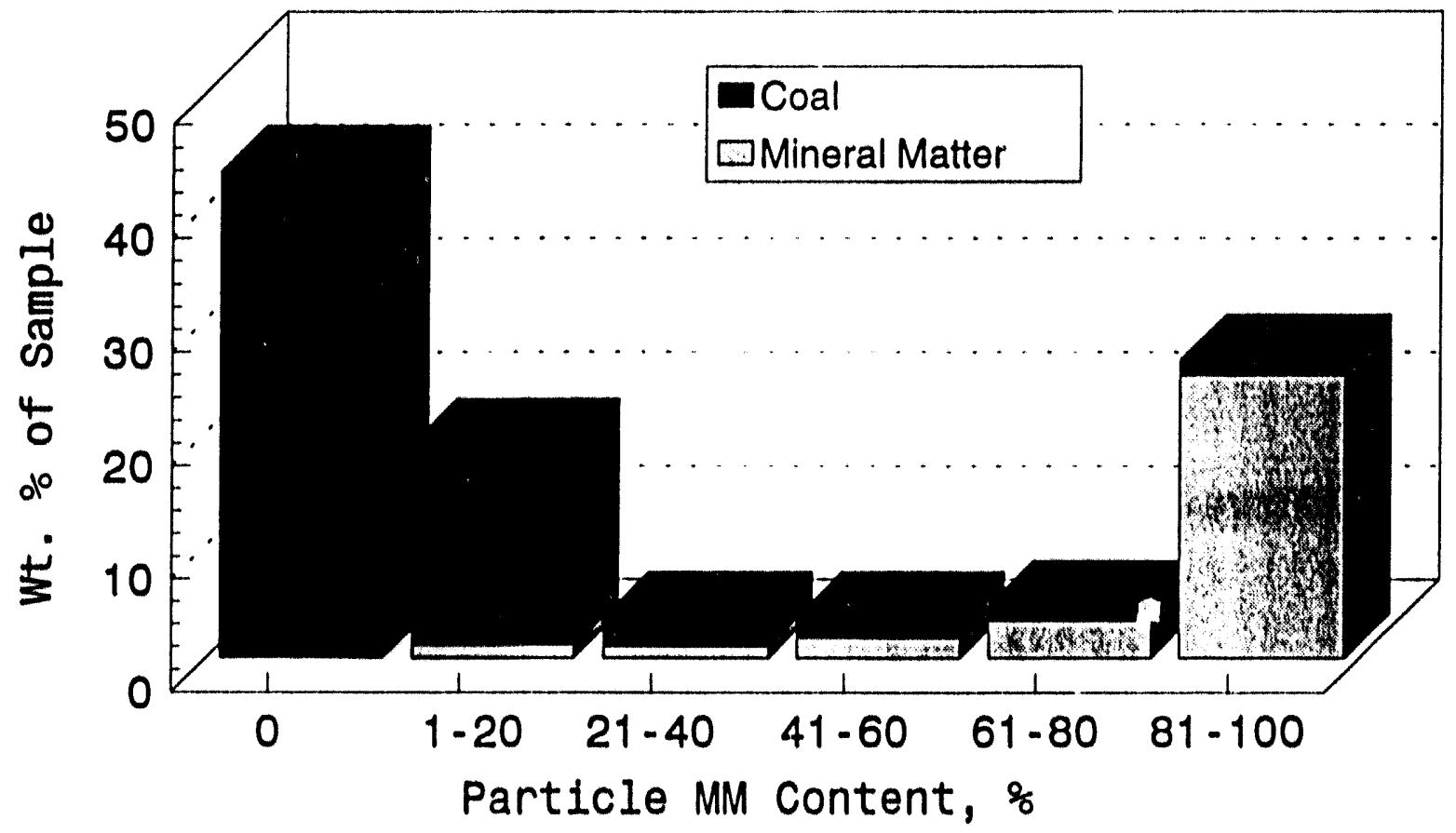

Fig. 2. Distribution of coal and mineral matter in 200-mesh Pittsburgh No. 8 coal based on mineral content of the particles.

Figure 4 indicates that the surface-based liberation may be the reverse of what was expected from the particle size data. Pyrite particles were signiflcantly larger than the clay particles; however, the clay particles seem to be preferentially liberated compared to the pyrite. This is undoubtedly due to the mode in which these minerals occur in the coal and the coal's behavior during grinding. It appears that 


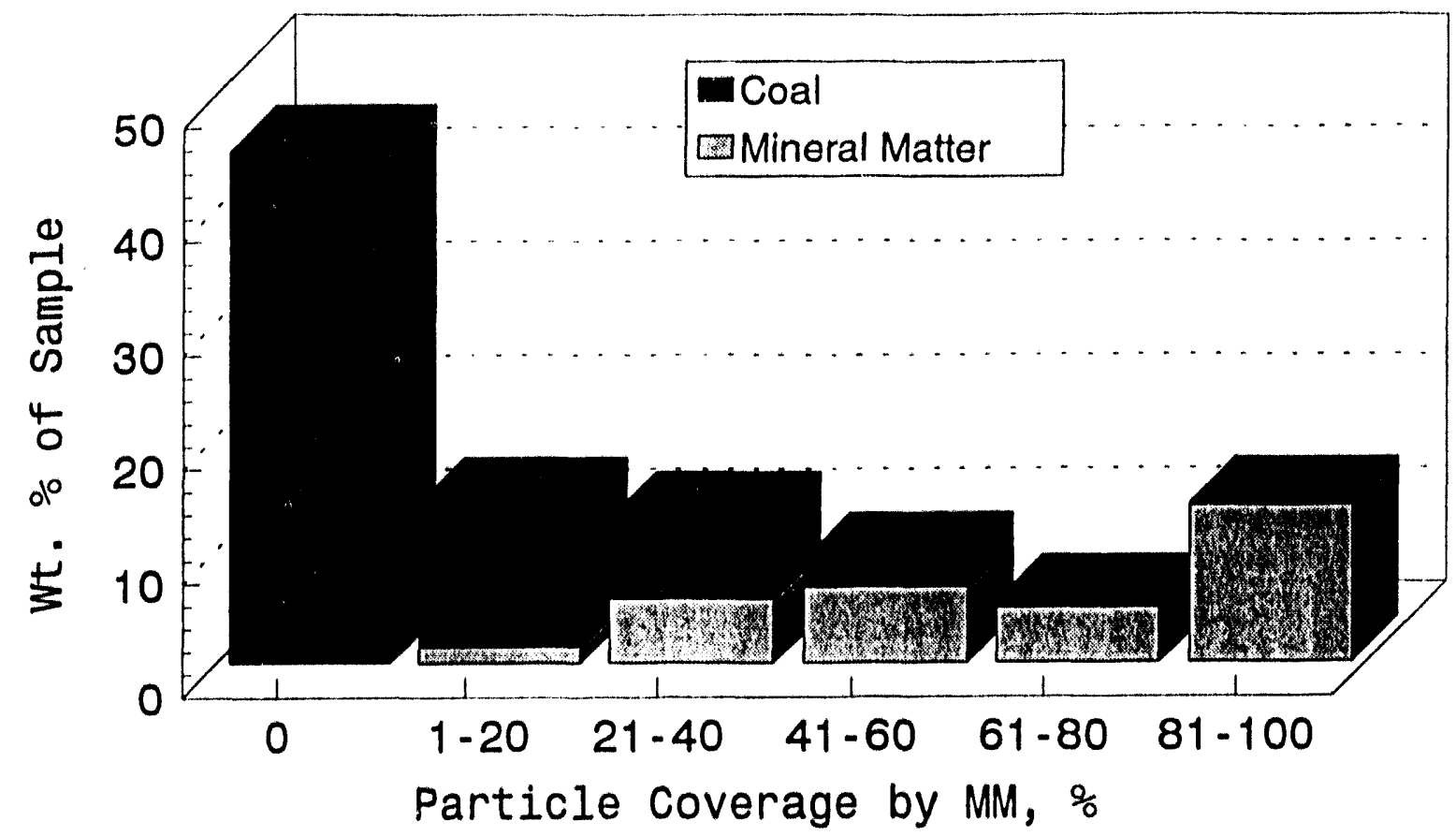

Fig. 3. Distribution of coal and mineral matter in 200-mesh Pittsburgh No. 8 coal based on mineral coverage of the particle surface.

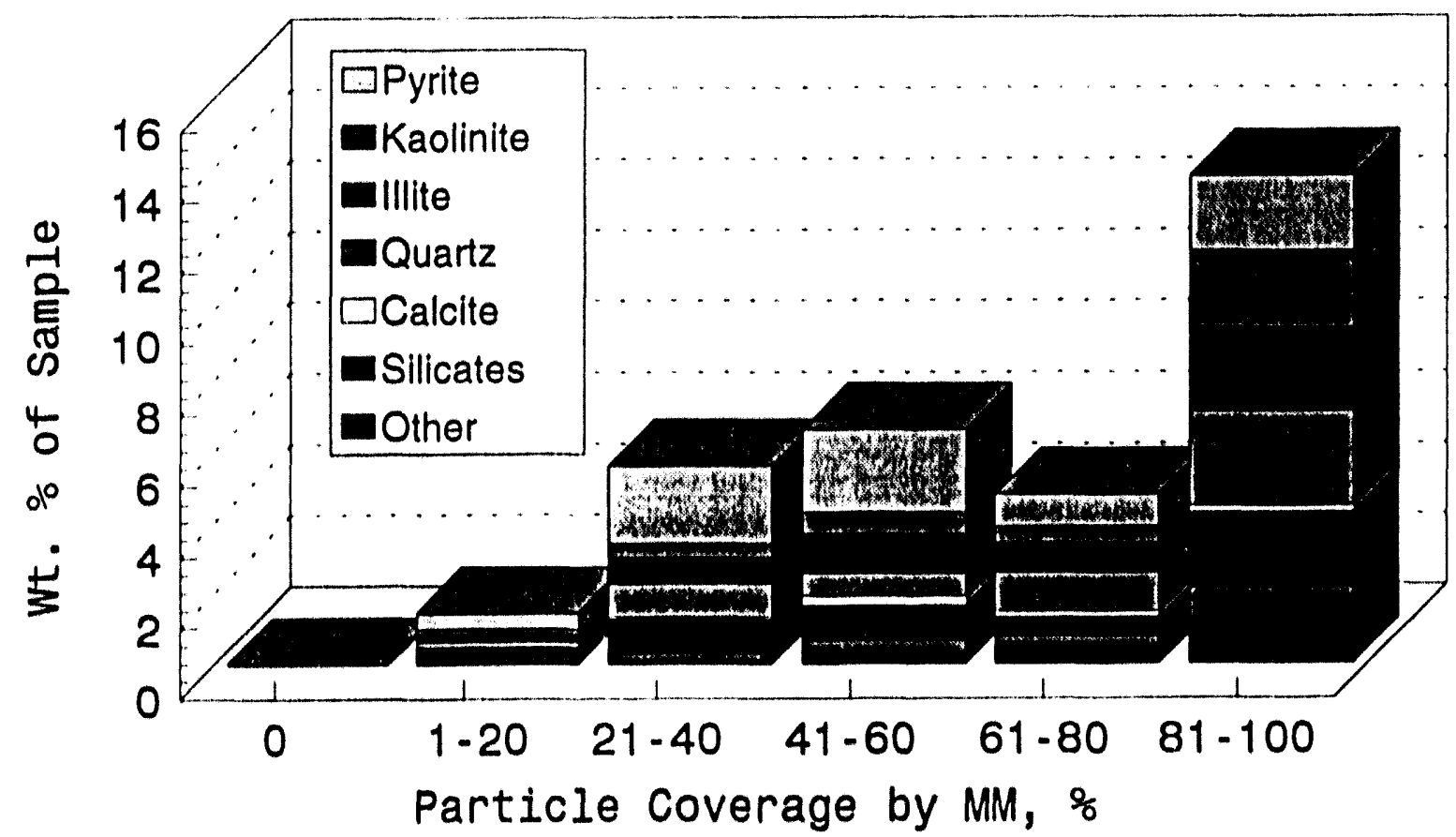

Fig. 4. Distribution of minerals in 200-mesh Pittsburgh No. 8 coal based on mineral coverage of the particle surface.

the clays occur in a form (cleat fillings or extraneous roof or floor material) that is easily liberated. Therefore, surface-based cleaning would be expected to be more effective on removing clays rather than pyrite from this coal.

Figure 5 shows the coal recovery (MAF basis) and mineral rejection predicted from the SEM-AIA results. Predictions were derived from AIA results assuming that it 
was possible to split samples according to points along the axes of Figures 2 and 3 . It appears that under ideal conditions density-based cleaning (Figure 2) has more potential for obtaining a clean product at high recovery than does surface-based cleaning (Flgure 3 ). In addition, it appears that pyrite rejection using a surfacebased process would be much lower than rejection of mineral matter in general.

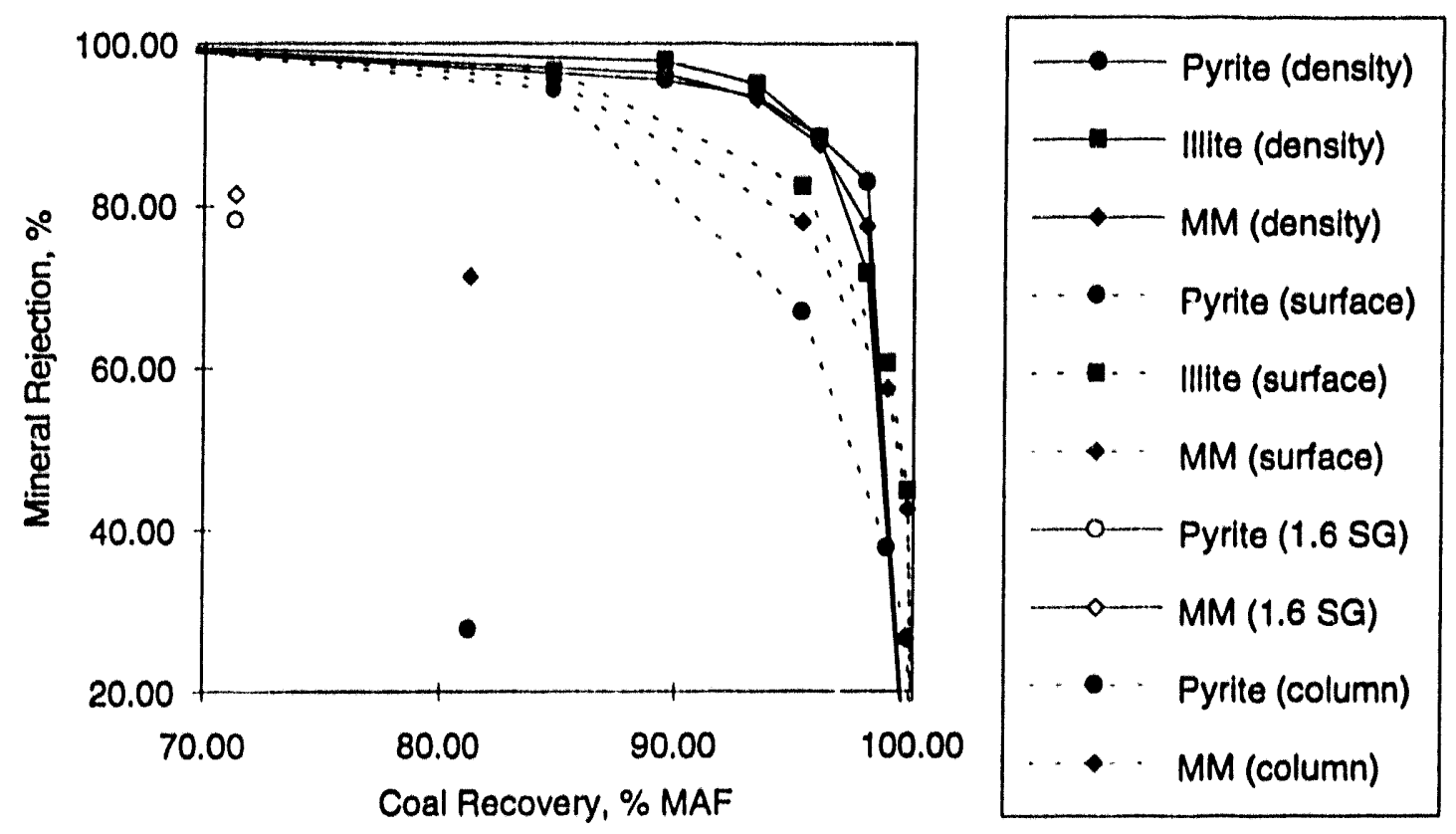

Fig. 5. Rejection of mineral matter as a function of combustible recovery for 200 mesh Pittsburgh No. 8 coal.

Figure 5 also shows the recovery and rejection data from a column flotation run and from a float-sink separation at 1.6 specific gravity. Both sets of results fall below the predicted curves indicating either poor performance in the actual separations or overestimation of the cleaning potential by the SEM method, or both. However the general SEM predictions were borne out, especially that the rejection of pyrite is much poorer by column flotation than by density separation. It appears that other factors such as the flotability of pyrite are also leading to the poor rejection of pyrite besides the incomplete liberation noted by SEM.

\section{CONCLUSIONS}

The analysis of coal-mineral association by SEM-AIA has been demonstrated with application to both density- and surface-based coal cleaning. Although the ability of the technique to provide quantitative predictions may be limited, the technique does appear capable of qualitatively predicting differences in cleaning behavior due to liberation effects since it provides detailed information for each mineral. This was seen in the poor liberation of pyrite compared to minerals in general for a 200-mesh sample of Pittsburgh No. 8 coal.

The association characteristics of minerals with the coal again suggest the efficacy of combined density- and surface-based methods for optlmal cleaning. Density- 
based methods which were effective in rejecting pyrite could be combined with surface-based methods for the removal of fine clays and other minerals.

The nature of the AIA-SEM technique and its ability to provide detailed information make it useful for other applications. The technique could also be used to characterize the process streams to check on the misplacement of particles and to suggest means for further improving the separation. Also, since the identity and size of the component grains in a composite particle are measured, numerous other applications are conceivable such as predicting ash chemistry for individual particles from transformations of the original minerals.

\section{ACKNOWLEDGEMENTS}

Ames Laboratory is operated for the U.S. Department of Energy by lowa State University under Contract No. W-7405-ENG-82. This work was supported by the Assistant Secretary for Fossil Energy through the Pittsburgh Energy Technology Center.

The assistance of James Pollard, Brian Poole, Robert Dawson, and Bogdan Slomka in the preparation of float-sink splits and in the operation of the column flotation system is gratefully acknowledged.

\section{References}

1. F.E. Huggins, G.P. Huffman, and R.J. Lee, Scanning Electron Microscopebased Automated Image Analysis (SEM-AIA) and Mossbauer Spectroscopy, in Coal and Coal Products: Analytical Characterization Techniques (ACS Symposium Series 205), E.L. Fuller, Jr. ed., American Chemical Society, Washington, D.C., 1982, pp. 239-258.

2. W.E. Straszheim and R. Markuszewskl, SEM-AIA Measurement of the Association of Mineral Matter with the Organic Cual Matrix for Predicting Fine Coal Cleanability, Coal Preparation - A Multinational Journal, 10 (1992), 59-75.

3. W.E. Straszheim, K.A. Younkin, R.T. Greer, and R. Markuszewski, Mounting Materials for SEM-based Automated Image Analysis of Coals, Scanning Microscopy, 2(3) (1988), 1257-1264.

4. W.E. Straszheim and R. Markuszewski, Prediction and Evaluation of Coal Cleanability, Fossil Energy Quarterly Report, Aprll 1 - June, 1991, Ames Laboratory, lowa State University, Ames, IA.

\section{DISCLAIMER}

This report was prepared as an uccount of work sponsored by an agency of the United States This report was prepared as anited States (Government nor any agency thereof, nor any of their employees, makes any warranty, express or implied, or ussumes any legal liability or responsiemployees, makes any warranty, express or implied, or assumes any legal inability or responat bility for the accuracy, completeness, or usefulness of any information, appares, product, or process disclosed, or represents that its use would not infringe privately owned rights. Refor once herein to any specific commercial product, process, or servico by itade nase, lnatomat, manufacturer, or otherwise does not necessarily constitute or imply its endorsement, recommendation, of favoring by the United States Government of any agency thereof. The views and opinions of authors expressed herein do not necessarily stale or reflect those of the United States Government of any agency thereof. 

